UDC 582.28(470.45)

LBC 28.591(2P-4Вог)

\title{
PRELIMINARY TAXONOMIC COMPOSITION OF MYCOBIOTA OF XYLOTROPHIC FUNGI OF THE HALF ISLAND SAREPTA CITY OF VOLGOGRAD
}

\author{
Nadezhda S. Kuragina \\ Volgograd State University, Volgograd, Russian Federation \\ Vadim A. Sagalaev \\ Volgograd State University, Volgograd, Russian Federation \\ Ol'ga V. Kulakova \\ Volgograd State University, Volgograd, Russian Federation
}

\begin{abstract}
The study area is the half island Sarepta, located on the territory of Krasnoarmeisky district of Volgograd. The study of the biota of fungi of the territory was held for the first time. The collection and processing of material was carried out according to the method A. S. Bondartsev and P. A. Singer. Identification of samples was carried out by standard methods in the laboratory of Experimental biology of Volgograd state University (VolSU) with the use of domestic and foreign determinants. The collected mushroom species stored in the herbarium of the VolSU. As a result of preliminary mycological studies in the period from September to November 2017 revealed 33 species of xylotrophic fungi. The greatest number of species was recorded in the ash trees and sokolnikah on wood in various stages of decomposition: the dry and dead trunks, branches, stumps. The article presents an annotated list of fungi with the indication of habitat, substrate timing, date of collection at a single discovery, the sample number in the Mycological herbarium of the VolSU and the name of the collector, if the collection was not carried out by the authors. Species names are arranged alphabetically and are aligned with the international electronic database CABI «IndexFungorum» (www.indexfungorum.org) as of February 2018.
\end{abstract}

Key words: xylotrophic mushrooms, half island Sarepta, Krasnoarmeysky district, the city of Volgograd, mycobiota, taxonomic analysis, mycological herbarium, substrate.

\section{ПРЕДВАРИТЕЛЬНЫЙ ТАКСОНОМИЧЕСКИЙ ОБЗОР МИКОБИОТЫ КСИЛОТРОФНЫХ ГРИБОВ ПОЛУОСТРОВА САРЕПТСКОГО ГОРОДА ВОЛГОГРАДА}

\author{
Надежда Сергеевна Курагина \\ Волгоградский государственный университет, г. Волгоград, Российская Федерация \\ Вадим Александрович Сагалаев \\ Волгоградский государственный университет, г. Волгоград, Российская Федерация \\ Ольга Владимировна Кулакова \\ Волгоградский государственный университет, г. Волгоград, Российская Федерация
}


Аннотация. Район исследования - полуостров Сарептский, расположенный на территории Красноармейского района города Волгограда. Исследование биоты грибов данной территории было проведено впервые. Идентификация образцов осуществлялась стандартными методами в лаборатории «Экспериментальной биологии» Волгоградского государственного университета (ВолГУ). В результате предварительных микологических исследований в период с сентября по ноябрь 2017 г. выявлено 33 вида ксилотрофных грибов. Наибольшее количество видов было зафиксировано в ясенниках и осокорниках на валежной древесине. В статье представлен аннотированный список грибов с указанием местообитания, субстратной приуроченности, даты сбора при единичной находке, номера образца в Микологическом гербарии ВолГУ и фамилии сборщика, если сбор был осуществлен не авторами.

Ключевые слова: ксилотрофные грибы, полуостров Сарептский, Красноармейский район, город Волгоград, микобиота, таксономический анализ, микологический гербарий, субстрат.

Целью исследования явилось изучение видового состава ксилотрофных грибов полуострова Сарептского города Волгограда.

Материалы и методы исследования. Исследование микобиоты полуострова Сарептского проводилось в период с сентября по ноябрь 2017 года. Сбор и обработка материала осуществлялись по методике А. С. Бондарцева и Р. А. Зингера (1950). Идентификация образцов осуществлялась стандартными методами в лаборатории Экспериментальной биологии Волгоградского государственного университета (далее ВолГУ) с использованием отечественных и зарубежных определителей [1-15]. Собранные виды грибов хранятся в Микологическом гербарии ВолГУ.

Результаты и их обсуждения. В настоящей работе представлен аннотированный список, включающий 33 вида ксилотрофных грибов, выявленных на территории полуострова Сарептского Красноармейского района города Волгограда.

Наибольшее количество видов грибов отмечено в ясенниках и осокорниках на валежных ветвях и стволах.

Названия видов расположены по алфавиту и приведены в соответствии с международной электронной базой данных САВI «IndexFungorum» (www.indexfungorum.org) по состоянию на февраль 2018 г.

Аннотированный список составлен по следующей схеме: латинское название вида, местообитание (растительное сообщество), субстрат, дата сбора (при единичной находке), VolSU - номер образца в Микологическом гербарии ВолГУ. Если вид был собран не авторами, то указана фамилия сборщика.

Bjerkandera adusta (Willd.) P. Karst. ясенник, на поваленном стволе лиственного дерева, 24.11.2017, VolSU 1646.
Cellulariella warnieri (Durieu et Mont.) Zmitr. et Malysheva - осокорник с участием вяза, на валежных стволах Ulmus laevis, VolSU 1521. Собр. Голованова М. А.

Coprinellus micaceus (Bull.) Vigalys, Hopple et Jacq. Johnson - осокорник, около пней, VolSU 1535.

Flammulina velutipes (Curtis) Singer ивняк, на живом ослабленном стволе Salix alba, 24.11.2017, VolSU 1641.

Fomes fomentarius (L.) Fr. - осокорник, на сухостойных и валежных стволах Populus nigra, VolSU 1640.

Fomitiporia punctata (P. Karst.) Murrill осокорник с участием вяза, на живом ослабленном стволе Ulmus laevis, 29.09.2017, VolSU 1522.

Hapalopilus nidulans (Fr.) P. Karst. ясенник, на валежных ветвях Fraxinus lanceolata, VolSU 1555.

Irpex lacteus (Fr.) Fr. - заброшенный сад, на сухостойных ветвях Prunus spinosa, 15.09.2017, VolSU 1518 .

Laetiporus sulphureus (Bull.) Murrill ясенник с участием ивы, на живых ослабленных столах Salix alba, VolSU 1559.

Lentinus tigrinus (Bull.) Fr. - ивняк, на стволе ослабленных деревьев Salix alba, VolSU 1556.

Marasmius oreades (Bolton) Fr. - луг, на почве, VolSU 1561.

Peniophora incarnata (Pers.) P. Karst. ясенник, на валежной ветви на валежных ветвях Fraxinus lanceolata, VolSU 1530.

Peniophora limitata (Chaillet ex Fr.) Cooke ясенник, на валежной ветви на валежных ветвях Fraxinus lanceolata, VolSU 1514.

Phanerochaete sordida (P. Karst.) J. Erikss. et Ryvarden - осокорник с участием ясеня, на валежных ветвях Populus nigra, VolSU 1658. 
Phellinus igniarius (L.) Quйl. - ивняк, на стволе ослабленных деревьев Salix alba, VolSU 1558.

Ph. pomaceus (Pers.) Maire - заброшенный сад, на ветвях живых деревьев Prunus spinosa, VolSU 1516.

Phlebia subochracea (Alb. et Schwein.) J. Erikss. et Ryvarden - ясенник, на валежных ветвях и поваленном стволе Fraxinus lanceolata, VolSU 1659.

Pleurotus ostreatus (Jacq.) P. Kumm. ясенник с участием тополя и осокорник, на сухостойных, валежных стволах Populus nigra, VolSU 1635, 1638.

Pluteus cervinus (Schaeff.) P. Kumm. ясенник, на пне Fraxinus lanceolata, 13.10.2017, VolSU 1540.

Porostereum spadiceum (Pers.) Hjortstam et Ryvarden - осокорник с участием тополя, на валежных ветвях лиственных деревьях, VolSU 1642.

Polyporus squamosus (Huds.) Fr. - ивняк, на живых ослабленных стволах Salix alba, VolSU 1636.

Radulomyces confluens (Fr.) M. P. Christ. осокорник с участием ясеня, на валежных ветвях Populus nigra, VolSU 1533.

$R$. molaris (Chaillet ex Fr.) M. P. Christ. осокорник с участием ясеня, на валежных ветвях лиственного дерева, VolSU 1637.

Sarcodontia spumea (Sowerby) Spirin осокорник с участием вяза, на живом ослабленном стволе Ulmus laevis, VolSU 1520.

Schizophyllum amplum (Lév.) Nakasone ясенник с участием тополя и осокорник, на валежных и живых ветвях Fraxinus lanceolata, Populus nigra, VolSU 1560.

Sch. commune Fr. - ясенник с участием тополя и осокорник, на валежных ветвях и стволах Populus nigra, VolSU 1621.

Stereum subtomentosum Pouzar - ясенник, на валежных ветвях Fraxinus lanceolata, VolSU 1647.

Trametes hirsuta (Wulfen) Lloyd - ясенник с участием тополя, на валежных ветвях и пне лиственных деревьев, VolSU 1557.

T. ljubarskyi Pilát - ясенник, на валежном стволе лиственного дерева, 15.09.2017, VolSU 1517.

T. ochracea (Pers.) Gilb. et Ryvarden ясенник, на пне лиственного дерева, 15.09.2017, VolSU 1519.
T. trogii Berk. - ивняк, на валежных и сухостойных ветвях Salix alba, VolSU 1639.

T. versicolor (L.) Lloyd - ясенник, на пне лиственного дерева, 13.10.2017, VolSU 1543.

Volvariella bombycina (Schaeff.) Singer осокорник с участием ясеня, в комлевой части Populus alba, 13.10.2017, VolSU 1562.

Таким образом, в результате таксономического анализа микобиоты полуострова Сарептского города Волгограда было выявлено 33 вида грибов. Основным субстратом является древесина на различной стадии разложения: сухостойные и валежные стволы, ветви, пни.

Авторы выражают глубокую признательность за помощь в сборе грибов М.А. Головановой.

\section{СПИСОК ЛИТЕРАТУРЫ}

1. Бондарцев, А. С. Руководство по сбору высших базидиальных грибов для научного из изучения / А. С. Бондарцев, Р. А. Зингер // Труды Ботанического института им. В. Л. Комарова.- 1950. Сеp. 2. Вып. 6. - С. 499-543.

2. Бондарцев, А. С. Трутовые грибы европейской части СССР и Кавказа / А.С. Бондарцев. - Л. : AHCCCP, 1953. - $1106 \mathrm{c}$.

3. Бондарцева, М. А. Определитель грибов СССР. Порядок афиллофоровые / М. А. Бондарцева, Э. Х. Пармасто. - Л. : Наука, 1986. - Вып. 1. - 192 с.

4. Бондарцева, М. А. Определитель грибов России. Порядок афиллофоровые / М. А. Бондарцева. - СПб. : Наука, 1998. - Вып. 2. - 391 с.

5. Васильков, Б. П. Съедобные и ядовитые грибы средней полосы европейской части России: Определитель / Б. П. Васильков. - СПб. : Наука, 1995. $-189 \mathrm{c}$.

6. Коткова, В. М. Трутовые грибы: материалы международного курса по экологии и таксономии дереворазрушающих базидиомицетов в ЦентральноЛесном заповеднике : учеб. пособие / В. М. Коткова, Т. Ниемеля, И. А. Винер, Д. С. Щигель, А. В. Кураков. - Хельсинки : Helsinki University Printing House, 2015. $-95 \mathrm{c}$.

7. Леонтьев, Д. В. Флористический анализ в микологии / Д. В. Леонтьев. - Харьков : ПП «РанокНТ», 2008. $-110 \mathrm{c}$.

8. Мухин, В. А. Полевой определитель труговых грибов / В. А. Мухин. - Екатеринбург, 1997. $104 \mathrm{c}$.

9. Переведенцева, Л. Г. Определитель грибов (агарикоидные базидиомицеты) / Л. Г. Переведенцева. - М. : Товарищество научных изданий КМК, 2015. $-119 \mathrm{c}$. 
10. Стороженко, В. Г. Атлас-определитель дереворазрушающих грибов лесов Русской равнины / В. Г. Стороженко, В. И. Крутов, А. В. Руоколайнен, В. М. Коткова, М. А. Бондарцева. - М. : Товарищество научных изданий КМК, 2014. - 195 с.

11. Bernicchia, A. Fungi Europaei / A. Bernicchia, S. P. Gorjon // Corticiaceae s. 1. Alassio: Edizioni Candusso. - 2010. - Vol. 12. - P. 1008.

12. Ryvarden, L. The genera of Polypores / L. Ryvarden. - Oslo : Fungiflora, 1991. - 363 p.

13. Ryvarden, L. European polypores. Part 1. Abortiporus-Lindtneria / L. Ryvarden, R. L. Gilbertson. Oslo : Fungiflora, 1993.-P. 1-387.

14. Ryvarden, L. European polypores. Part 2. Meripilus-Tyromyces / L. Ryvarden, R. L. Gilbertson. Oslo : Fungiflora, 1994. - P. 388-743.

15. Ryvarden, L. Poroid fungi of Europe. Synopsis Fungorum 31 / L. Ryvarden, I. Melo. - Oslo : Fungiflora, 2014. $-456 \mathrm{p}$.

\section{REFERENCES}

1. Bondarcev A.S., Zinger R.A. Rukovodstvo po sboru vysshih bazidial'nyh gribov dlja nauchnogo iz izuchenija [Guidance on the collection of higher basidiomycetes for the scientific study of], Trudy Botanicheskogo instituta im. V. L. Komarova, 1950, ser. 2. vol. 6, pp. 499-543.

2. Bondarcev A.S. Trutovye griby evropejskoj chasti SSSR i Kavkaza [Sponk mushrooms of the European part of the USSR and Caucasus]. L., USSR Academy of Sciences, 1953, $1106 \mathrm{p}$.

3. Bondarceva M.A., Parmasto Je.H. Opredelitel' gribov SSSR. Porjadok afilloforovye [Determinant of mushrooms of the USSR. Order aphyllophorales]. L., Science, 1986, Vol. 1, 192 p.

4. Bondarceva M.A. Opredelitel' gribov Rossii. Porjadok afilloforovye [Keys to fungi of Russia. Order aphyllophorales]. Spb., Science, 1998, Vol. 2, 391 p.

5. Vasil'kov B.P. S'edobnye i jadovitye griby srednej polosy evropejskoj chasti Rossii: Opredelitel' [Edible and poisonous fungi of the medium belt of the
European part of Russia: the Determinant]. Spb., Science, 1995, 189 p.

6. Kotkova V.M., Niemelja T., Viner I.A., Shhigel' D. S., Kurakov A.V. Trutovye griby: materialy mezhdunarodnogo kursa po jekologii $i$ taksonomii derevorazrushajushhih bazidiomicetov $v$ Central'no-Lesnom zapovednike. Uchebnoe posobie [Polypore fungi: materials of the international course on ecology and taxonomy of lingnicolous basidiomycetes in the Central Forest reserve. Tutorial]. Helsinki, Helsinki University Printing House, 2015, 95 p.

7. Leont'ev D. V. Floristicheskij analiz v mikologii [Floral analysis in Mycology]. Kharkov, PP «Ranok-NT», 2008, 110 p.

8. Muhin V. A. Polevoj opredelitel' trutovyh gribov [Field guide bracket-fungus]. Ekaterinburg, 1997, 104 p.

9. Perevedenceva L.G. Opredelitel' gribov (agarikoidnye bazidiomicety) [Determinant of mushrooms (basidiomycetes agaricaceae)]. Moscow, Partnership of scientific publications KMK, 2015, 119 p.

10. Storozhenko V.G., Krutov V.I., Ruokolajnen A.V., Kotkova V.M., Bondarceva M A. Atlas-opredelitel' derevorazrushajushhih gribov lesov Russkoj ravniny [Atlas-the determinant of wood-destroying mushrooms in the forests of The Russian plain]. M., Partnership of scientific publications KMK, 2014, 195 p.

11. Bernicchia A., Gorjon S. P. Fungi Europaei. Vol. 12. Corticiaceae s. 1. Alassio, Edizioni Candusso, 2010, 1008 p.

12. Ryvarden L. The genera of Polypores.Oslo, Fungiflora, 1991, 363 p.

13. Ryvarden L., Gilbertson R. L. European polypores. Part 1. Abortiporus-Lindtneria. Oslo, Fungiflora, 1993, pp. 1-387.

14. Ryvarden L., Gilbertson R. L. European polypores. Part 2. Meripilus-Tyromyces. Oslo, Fungiflora, 1994, pp. 388-743.

15. Ryvarden L., Melo I. Poroid fungi of Europe. Synopsis Fungorum 31. Oslo, Fungiflora, 2014, 456 p.

\section{Information about the Authors}

Nadezhda S. Kuragina, Assistant, Department of biology, Volgograd State University, prosp. Universitetskij, 100, 400062 Volgograd, Russian Federation, pipenko87@mail.ru.

Vadim A. Sagalaev, Doctor of biology sciences, Professor, Head of Department of biology, Volgograd State University, prosp. Universitetskij, 100, 400062 Volgograd, Russian Federation, bot@volsu.ru.

Ol'ga V. Kulakova, Student of a bachelor degree «Biology», Department of biology, Volgograd State University, prosp. Universitetskij, 100, 400062 Volgograd, Russian Federation, bot@volsu.ru. 


\section{БИОЛОГИЯ И БИОТЕХНОЛОГИЯ}

\section{Информация об авторах}

Надежда Сергеевна Курагина, ассистент, кафедра биологии, Волгоградский государственный университет, просп. Университетский, 100, 400062 г. Волгоград, Российская Федерация, pipenko87@mail.ru.

Вадим Александрович Сагалаев, доктор биологических наук, профессор, зав. кафедрой биологии, Волгоградский государственный университет, просп. Университетский, 100, 400062 г. Волгоград, Российская Федерация, bot@volsu.ru.

Ольга Владимировна Кулакова, студентка бакалавриата «Биология», кафедра биологии, Волгоградский государственный университет, просп. Университетский, 100, 400062 г. Волгоград, Российская Федерация, bot@volsu.ru. 